\title{
Application of Fuzzy Control for Iron Ore Sintering Process*
}

\author{
By Munetake IWAMOTO,** Koukichi HASHIMOTO,** Mamoru INABA,** \\ Takashi KOBAYASHI,** Michinori HATTORI*** and Osamu KOMATSU***
}

\section{Synopsis}

In the iron and steel making shops, some processes are so complex that it is difficult to formulate precise control models. In such cases, process control is made on the basis of the skilled operator's heuristic knowledge. However, utilization of skilled operator's heuristic knowledge is one of the major problems to control the process precisely. In the fuzzy set theory, skilled operator's knowledge is expressed as membership functions to control the process as well as skilled operators.

The fuzzy set theory was applied to the on-line control of return fine hopper level at the sintering plant in Fukuyama Works, Nippon Kokan K.K. This was the first application of fuzzy control to the practical operation. The commercial operation has started in August 1986. As the result, the deviation of return fine hopper level decreased from 12 to $4 \% / \mathrm{h}$ and the amount of return fine decreased by about $2 \mathrm{~kg} / \mathrm{t}$-sinter.

Key words: fuzzy control; sintering process; return fine; raw material.

\section{Introduction}

The iron ore sintering process produces continuously sinter ore with various kinds of iron fine ore as the raw material and lime stone as the binder. This process has two major subjects. One is the stabilization of operation to produce uniformly grain-sized and strong sinter ore as the ferrous burden of blast furnace. Another is the optimization of process to minimize the production cost under various conditions and processing throughout the whole iron works.

Various sensors and on-line control models based on the statistical analysis and metallurgical theory have been developed in Fukuyama Works in order to stabilize sinter ore quality and to save energy and applied to practical operation satisfactorily.

However, the iron ore sintering process is subjected to a variety of changes in raw materials and operation. Furthermore it is a slow process with a long dead time so that it is difficult to formulate precise mathematical models for some parts in the process. The operation of such parts is performed on the skilled operator's judgment based on their heuristic knowledge. The typical example is the return fine feeding control, which will be discussed on the basis of fuzzy set theory in this paper.

\section{Outline of Iron Ore Sintering Process}

Figure 1 shows the configuration of sensors and control system of the No. 5 sintering plant at Fukuyama Works. The sintering plant is divided by functions into 5 sub-processes such as the blending equipment, granulating equipment, charging equipment, sintering machine, and cooler equipment. The blending equipment has 14 blending hoppers for 5 types of raw materials, which are fine iron ore, lime stone, burnt lime, return fine, and fine coke, and has constant feed weighers designated as CFW in the figure. These raw materials are delivered by con-

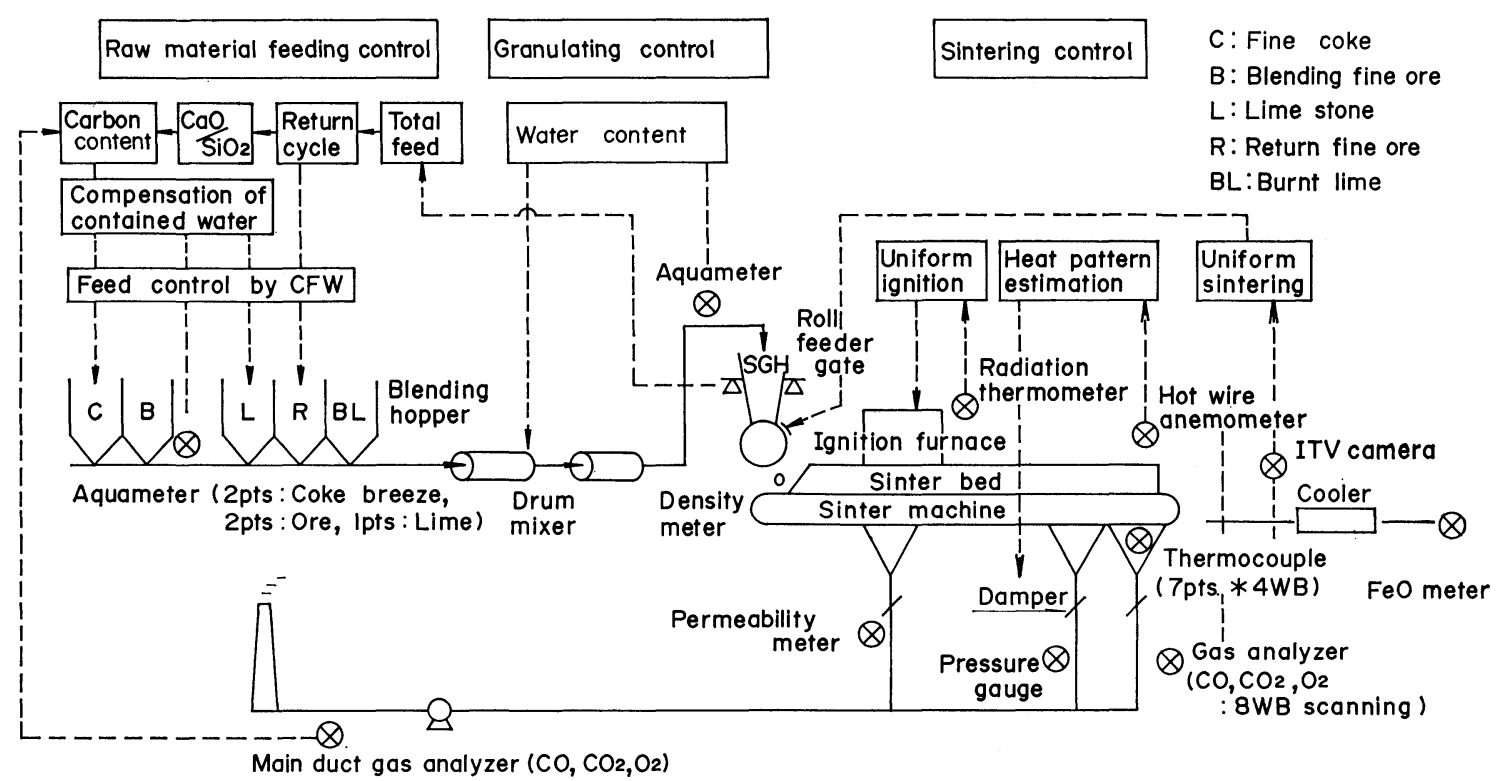

Fig. 1. Sensors and control system at No. 5 sintering process.

\footnotetext{
* Based on the paper presented to the 112th ISIJ Meeting, October 1986, S799, at Nagoya University in Nagoya. Manuscript received on August 26, 1987; accepted in the final form on December 11, 1987. (C) 1988 ISIJ

** Process Control Department, Fukuyama Works, Nippon Kokan K.K., Kokan-cho, Fukuyama 721.

*** Iron Making Department, Fukuyama Works, Nippon Kokan K.K., Kokan-cho, Fukuyama 721.
} 
stant feed weighers according to the following equation.

$$
C i=B \times R i /(100-M i)
$$

Here, $B:$ total feeding amount of the raw materials $(\mathrm{t} / \mathrm{h})$

$C i$ : feeding amount of $i$-th blending hopper $(\mathrm{t} / \mathrm{h})$

$R i$ : feeding ratio of $i$-th blending hopper $(\%)$

$M i$ : moisture content of raw material, which is stored in $i$-th blending hopper (\%).

The raw materials are then mixed and granulated by drum mixers and sent to the surge hopper.

The granulated raw material in the surge hopper, $\mathrm{SGH}$, is fed by the roll feeder to the pallet of the sintering machine through the dividing gates, which improves the uniformity of bed across the pallet width. The fine coke in the sinter bed is ignited by the coke oven gas (COG) burners, which are set across the pallet. The fine coke in the sinter bed burns from the surface toward the bottom by the downward air flow through the wind boxes, which are lined up along the moving direction of pallet in the sintering machine.

After hot sinter ore is discharged, it is crushed, cooled, and screened. The sinter larger than $4 \mathrm{~mm}$ is sent to the blast furnace. However the sinter below $4 \mathrm{~mm}$ is sent back to the blending hoppers as the raw material, which is called the return fine ore.

This iron ore sintering process has the following characteristics.

(1) Raw material has both a slowly changing factor such as composition and grain size and a quickly changing factor such as moisture.

(2) Raw material composition and grain size segregation across the width and height of sinter bed always fluctuates, because of the change in surge hopper level, raw materials adherence and some other causes. Therefore the wind flow distribution through the sinter bed always changes in the moving direction.

(3) Sinter size changes slowly because of the varying conditions of screener and crusher.

(4) The whole sintering process is dominated by the metallurgical reaction which has a long dead time.

The following control models for such characteristic sintering process have been applied to practical operation successfully. Table 1 shows these control models.

(1) In the blending process, the feeding ratio of each hopper and total feeding amount is controlled so that the basicity, $\mathrm{CaO} / \mathrm{SiO}_{2}$, carbon content in the raw material, and surge hopper level become constant. The statistical theory is used in the basicity control model. The mass balance model is used in the carbon content control model. The sampling theory is used in the surge hopper level control model.

(2) In the granulating process, the water flow ratio is controlled so that the water content in the raw material becomes constant. The sampling theory is used in this model.
Table 1. The conventional control models.

\begin{tabular}{|c|c|c|c|}
\hline Process & Control item & Control target & Method \\
\hline \multirow{3}{*}{$\begin{array}{l}\text { Raw material } \\
\text { blending }\end{array}$} & $\begin{array}{l}\text { Lime feeding } \\
\text { ratio }\end{array}$ & $\mathrm{CaO} / \mathrm{SiO}_{2}$ content & $\begin{array}{l}\text { Statistical } \\
\text { theory }\end{array}$ \\
\hline & $\begin{array}{l}\text { Coke feeding } \\
\text { ratio }\end{array}$ & Carbon content & $\begin{array}{l}\text { Mass } \\
\text { balance }\end{array}$ \\
\hline & $\begin{array}{l}\text { Total feeding } \\
\text { amount }\end{array}$ & Surge hopper level & $\begin{array}{l}\text { Sampling } \\
\text { theory }\end{array}$ \\
\hline Granulation & $\begin{array}{l}\text { Water flow } \\
\text { ratio }\end{array}$ & Water content & $\begin{array}{l}\text { Sampling } \\
\text { theory }\end{array}$ \\
\hline \multirow{3}{*}{ Sintering } & $\begin{array}{l}\text { COG valve } \\
\text { opening }\end{array}$ & Uniform ignition & $\begin{array}{l}\text { Distribu- } \\
\text { tion }\end{array}$ \\
\hline & $\begin{array}{l}\text { Divided gate } \\
\text { opening }\end{array}$ & Uniform sintering & $\begin{array}{l}\text { Distribu- } \\
\text { tion }\end{array}$ \\
\hline & $\begin{array}{l}\text { Wind box } \\
\text { damper } \\
\text { opening }\end{array}$ & $\begin{array}{l}\text { Optimum heat } \\
\text { pattern estima- } \\
\text { tion }\end{array}$ & $\begin{array}{l}\text { Heat } \\
\text { balance }\end{array}$ \\
\hline
\end{tabular}

(3) In the sintering process, the GOG valve opening, the divided gates opening, and the wind box damper opening are controlled for uniform ignition, uniform sintering, and optimum heat pattern, respectively. The valve opening of COG burners is calculated by the computer according to the distribution of surface temperature of sinter bed at the exit of ignition furnace. The opening of the dividing gates is also calculated by the computer according to the distributions of charging density, exhaust gas temperature in the wind boxes, and combustion zone at the end point of sintering machine. The distribution of the combustion zone is measured by a thermo-camera at the discharging site of sinter. The opening of the wind box damper is calculated from the data of hot wire anemometers, pressure gauges and gas analyzer by using the heat balance model.

However construction of precise models is difficult to stabilize the rate of return fine ore and to optimize the heat index, permeability index and quality index in whole iron ore sintering operation. The skilled operator's heuristic knowledge has been used to optimize the process.

Figure 2 shows the recycle flow of return fine ore. In general, the rate of return fine ore increases when sinter quality becomes bad, and decreases when its mixing ratio in raw materials of sinter increases. Therefore it is important to stabilize the recycled amount of return fine ore.

However the amount of return fine ore is not always constant because of the fluctuation in raw materials adherence, conditions of sintering operation, and quality of sinter ore. The whole iron ore sintering process has 4 to $5 \mathrm{~h}$ of dead time. It is therefore difficult to make a precise model by the conventional method.

For this reason, the operator assumes the amount of return fine ore in accordance with the return fine hopper level and level transition, and determine the return fine feeding ratio from their operational experiences. 


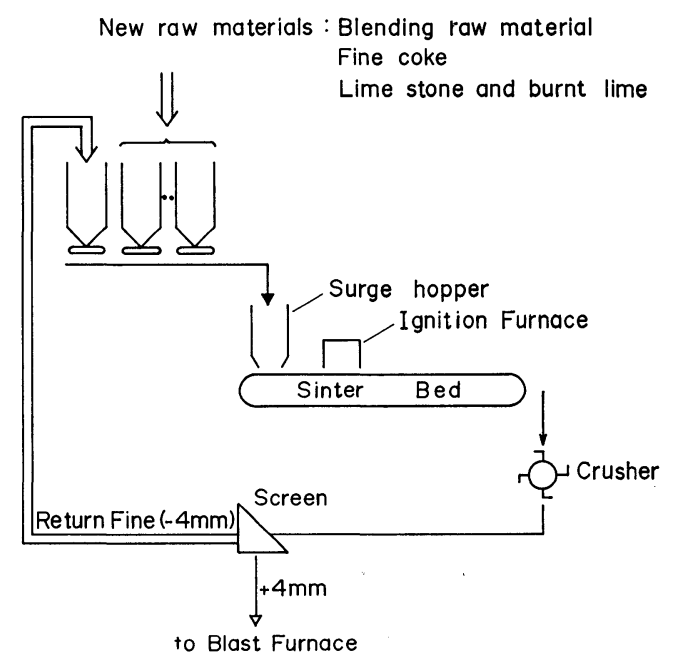

Fig. 2. Recycle flow of return fine.

\section{On-line Control of Return Fine Hopper Lev- el by Fuzzy Set Theory}

In the fuzzy set theory, we can make the most use of the skilled operator's heuristic knowledge with the membership function, and realize the control system as if the skilled operator is operating.

The conventional set theory defines clearly the elements which belong to an aggregate. However, the fuzzy set theory defines the extent of the elements which belong to an aggregate in terms of membership function. ${ }^{1)}$ Figure 3 shows the difference of concept between the conventional set theory and the fuzzy set theory. The conventional set theory strictly defines the temperature $25^{\circ} \mathrm{C}$ as hot. However, the fuzzy set theory, using the membership function, distinguishes the concept as hot, medium, and cold. Therefore the degree of hot, medium, and cold become 0.9 , 0.1 , and 0.0 , if the temperature is $30^{\circ} \mathrm{G}$. The conventional set theory defines the two values as zero or 1 at $30^{\circ} \mathrm{G}$, respectively, but the fuzzy set theory can define any values using the membership function. So it can define operator's heuristic knowledge flexibly.

The fuzzy set theory was used in industry for the first time in 1974 by Mandani. ${ }^{2)}$ Thereafter, many researches were reported. In particular, Ostergaard and Holmblad have succeeded in the application of fuzzy control to the cement kiln at F. L. Smidth Company of Denmark in 1982. ${ }^{3)}$

In Japan, it was applied to the control for injection of chemicals in water purifying plants ${ }^{4}$ and to the control of stopping position of trains. ${ }^{5)}$ Lately, it was applied to the continuous casting installations for quality diagnosis, and to planning of optimum saw cut of shape steel. ${ }^{6)}$

From this point of view, we tried to apply the fuzzy set theory to the return fine hopper level control, where it was difficult to systematize with the conventional method.

\section{Determination of Membership Function}

The point of fuzzy control is the membership function, which represents the skilled operator's heuristic knowledge. Knowledge of a few operators was a) Conventional

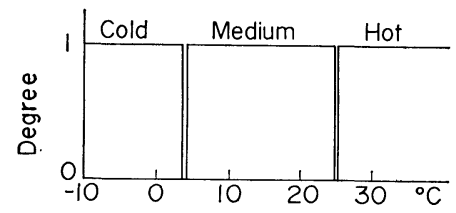

b) Fuzzy

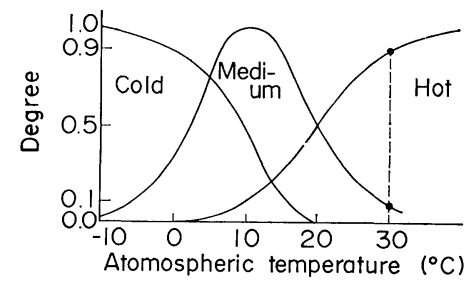

Fig. 3. Example of membership function.

collected shown in the Table 2. For example, the degree of small low is 0.75 and the degree of zero is 0.25 , when the surge hopper level is $37.5 \%$. It was converted into Table 3 by using the fuzzy set theory. Figure 4 shows the membership function for Table 3 based on the heuristic knowledge.

\section{Determination of Action Value}

The action value is determined from these membership function in accordance with the following procedures.

The value of $C k$ which represents the degree of the return fine hopper level, $x(\%)$, belonging to the $i$-th membership function, $L i$, and the changes of the return fine hopper level, $y(\% / \mathrm{h})$, belonging to the $j$-th membership function, $D L j$, can be expressed as the product $L i$ and $D L j$ in the range of combination indicated in Table 3.

$$
C k=L i(x) \times D L j(y) ; \quad i, j, k=1,5
$$

The function for action value of each combination, $a(z)$, is calculated with the maximum value of the product $C k$ and the $i$-th membership function of action, $A i$, where $z$ is the action value of return fine feeding ratio $(\%)$.

$$
a(z)=\operatorname{Max}(C k \times A i)
$$

The action value of return fine feeding ratio, $R$, is calculated as the center gravity of $a(z)$.

$$
R=\int z \times a(z) \times d z / \int a(z) \times d z
$$

For example, Table 2 shows that the action value is $-1 \%$, if the return fine hopper level is $37.5 \%$ and the level changes is $+1 \% / \mathrm{h}$ in the conventional set theory. On the other hand, in the fuzzy set theory, Fig. 4 shows that the degree at which $x$ belongs to $L 2$ is 0.75 and the degree at which $x$ belongs to $L 3$ is 0.25 , if the hopper level $x$ is $37.5 \%$. The degree at which $y$ belongs $D L 4$ is 1 and the degree at which $y$ belongs $D L 3$ is 1 , if the level changes $y$ is $+1 \% / \mathrm{h}$. The action value for $L 2, D L 4$ and $A 2$ is shown by the solid line, and the action value for $L 3, D L 3$ and $A 3$ is shown by broken lines. So the action value is cal- 
Table 2. The operator's heuristic knowledge.

\begin{tabular}{|c|c|c|c|c|c|c|c|c|c|}
\hline$x$ & $0 \sim 30$ & \multicolumn{2}{|c|}{$30 \sim 40$} & \multicolumn{3}{|c|}{$40 \sim 60$} & \multicolumn{2}{|c|}{$60 \sim 80$} & $80 \sim 100$ \\
\hline$y$ & - & $<0$ & $0<$ & $<-2$ & $-2<\mathrm{DL}<2$ & $2<$ & $<0$ & $>0$ & - \\
\hline$z$ & -2 & -2 & -1 & -1 & 0 & 1 & 1 & 2 & 2 \\
\hline
\end{tabular}

$x$ : Return fine hopper level (\%)

$z:$ Action value of return fine feeding ratio (\%)

Table 3. The fuzzy set theory.

\begin{tabular}{|c|c|c|c|c|c|c|c|c|c|}
\hline \multirow{3}{*}{$\begin{array}{l}L i \\
D L j \\
A i\end{array}$} & \multirow{2}{*}{$\begin{array}{l}L 1 \\
D L 2\end{array}$} & \multicolumn{2}{|c|}{$L 2$} & \multicolumn{3}{|c|}{$L 3$} & \multicolumn{2}{|c|}{$L 4$} & $L 5$ \\
\hline & & $D L 2$ & $D L 4$ & $D L 1$ & $D L 3$ & $D L 5$ & $D L 2$ & $D L 4$ & $D L 4$ \\
\hline & $A 1$ & $A 1$ & $A 2$ & $A 2$ & $A 3$ & $A 4$ & $A 4$ & $A 5$ & $A 5$ \\
\hline
\end{tabular}

$L i: \quad i$-th membership function for level

$A i: i$-th membership function for action
$L 1$ : very low
L2: small low
$D L 1, A 1:$ negative $D L 2, A 2:$ small nagative $D L 3, A 3:$ zero
$D L 1, A 1:$ negative $D L 2, A 2:$ small nagative $D L 3, A 3:$ zero
L3: medium
L4: small high
$L 5:$ very high
$D L 4, A 4:$ small positive
$D L 5, A 5$ : positive

$D L j: j$-th membership function for level changes
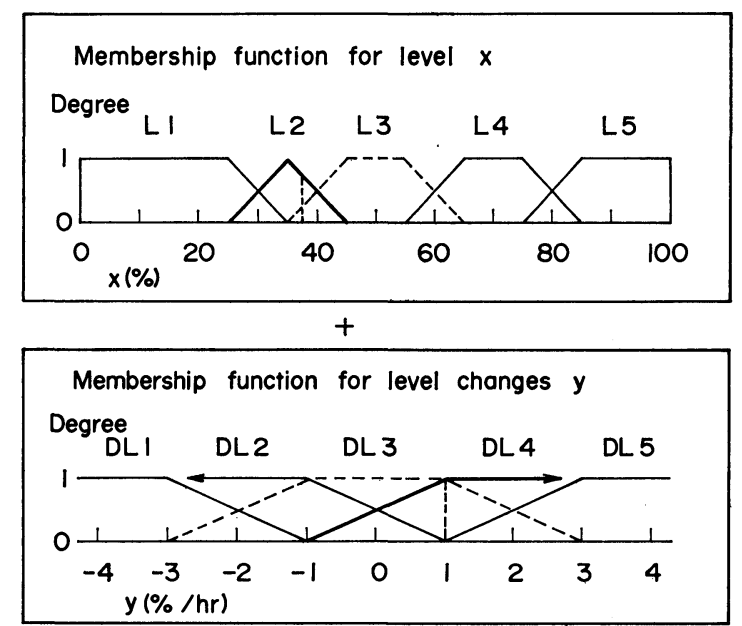

IF $\mathrm{Li}$ is --- and $\mathrm{DLj}$ is---, then $\mathrm{Z}=\mathrm{Ai}$ using following table

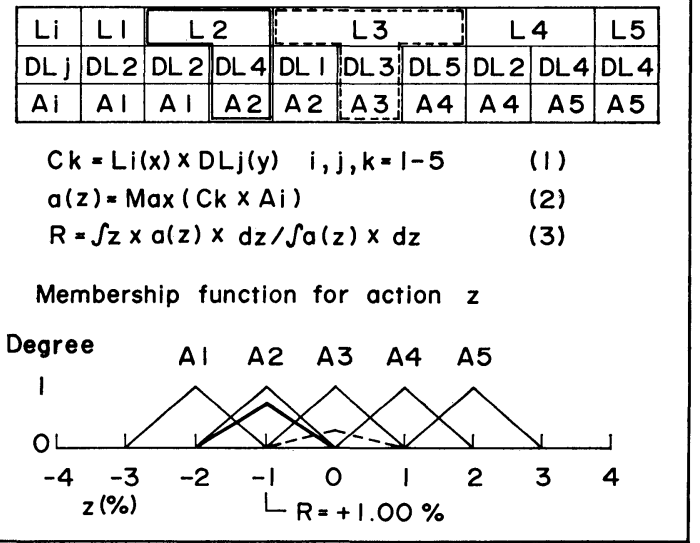

Fig. 4. Membership functions for level, level change, and action.

culated as $-1.00 \%$ for the center of gravity.

\section{Simulation Result}

Figure 5 shows the simulation result, when the hopper level is $37.5 \%$, and the level changes from -3 to $3 \%$. It shows the action is smooth and continuous compared with the conventional method.

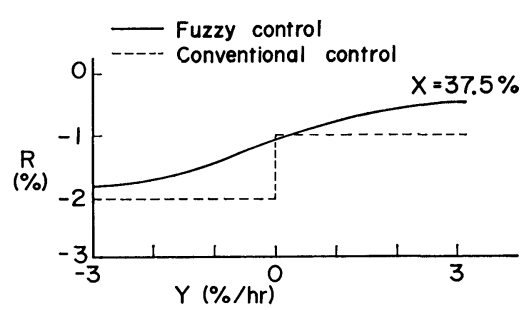

Fig. 5. Simulation result of fuzzy control.

a) Conventional control

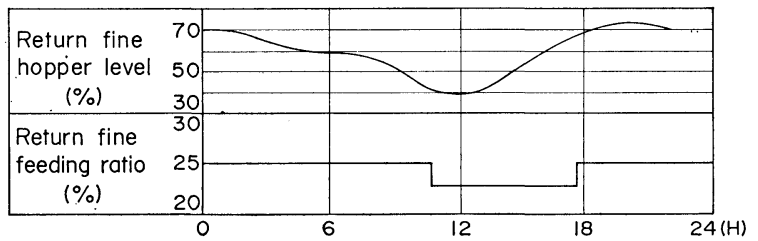

b) Fuzzy control

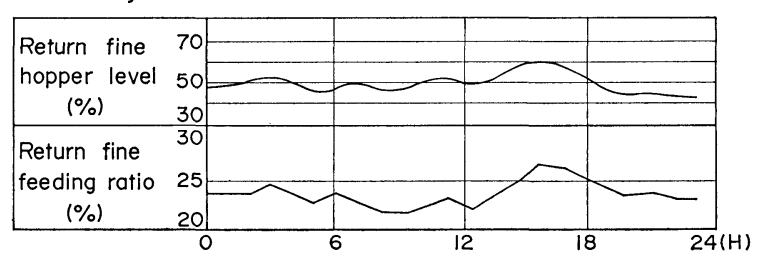

Fig. 6. Result of fuzzy control.

\section{Results of On-line Control}

By applying the fuzzy control model, the process can be controlled more smoothly and continuously than the most skillful operators. Figure 6 shows the results of on-line control. It shows that the deviation of return fine hopper level decreased from 12 to $4 \%$ and the amount of return fine ore decreased by about $2 \mathrm{~kg} / \mathrm{t}$-sinter. ${ }^{7)}$

As the result, the consumption of high quality iron fine and fine coke has been reduced to lead a considerable reduction of production cost.

\section{Conclusion}

The return fine hopper level on-line control model by the fuzzy set theory has been applied to practical 
operation successfully since its start in August 1987. As a results of applications, we recognized the following.

(1) It is not necessary for the fuzzy control system to make a precise model, so it is suitable for the complex process.

(2) Multi-dimensional problems are described by using a membership function.

\section{REFERENGES}

1) L. A. Zadeh: Fuzzy set, Information and control, 8 (1965).

2) E. H. Mandani: Int. J. Man-machine Studies, 7 (1975).
3) J. J. Ostergaard and L. P. Holmblad: Control of a Cement Kiln by fuzzy logic, Fuzzy information and decision processers, North-Holland Co., (1982), 389-399.

4) O. Yanagishita, O. Itoh and M. Kanno: Syst. Control, 28 (1984), 579

5) S. Yasunobu, S. Miyamoto and H. Ihara: Soc. Instrum. Control Eng., 19 (1983).

6) M. Kanno, H. Higashinaka and M. Sugimoto: Tetsu-toHagané, 68 (1985), S378.

7) M. Iwamoto, K. Hashimoto, M. Inaba, T. Kobayashi, M. Hattori and O. Komatsu: Nippon Kokan Tech. Rep., (1987), No. 50,1 . 